\title{
INTRODUCING GAP IN HAIR FOLLICLE ELECTROMAGNETISM AS PROPOSED MECHANISM FOR THE PRESENCE OF BIPOLAR ELECTRICAL CHARGES INHERENT IN THE HUMAN HAIR SHAFT
}

\author{
Abrahám A. Embí BS ${ }^{1} ه$ (iD) \\ 13442 SW 102 Lane, Miami,Florida 33186, United States
}

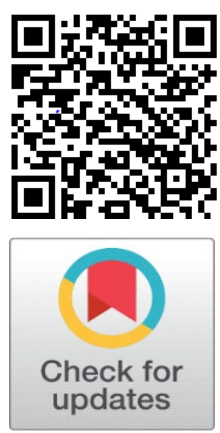

Received 5 September2021

Accepted 16 September2021

Published 30 September2021

CorrespondingAuthor

Abrahám A. Embí BS, embi21@att.net

DOI

10.29121/granthaalayah.v9.i9.2021. 4260

Funding: This research received no specific grant from any funding agency in the public, commercial, or not-for-profit sectors.

Copyright: (C) 2021 The Author(s). This is an open access article distributed under the terms of the Creative Commons Attribution License, which permits unrestricted use, distribution, and reproduction in any medium, provided the original author and source are credited.

\section{ABSTRACT}

The human hair consists of a follicle anchored in the skin and a protruding shaft, it has also been described as a miniorgan, having its own cell divisions, metabolism, and known to undergo aging stages; eventually reaching a point where the old hair sheds and a new hair growing cycle begins from the same follicular tissue. Using sophisticated magnetometers, magnetic field emitted by direct current (DC) in human hair follicles were detected and introduced in 1980. Most recently in 2015, a tabletop optical microscopy method was developed and published in 2016, thus allowing for the detection of hair follicles and shaft magnetic fields. Qualitative images are presented where the bipolar electrical property of the shaft is documented. This finding was inferred since blood tissue carries a negative charge, thus repelled by an equal charge; experiments support a positive (+) field as triggering coagulation. The shaft is repeatedly shown in experiments to express a contralateral positive side inducing clots. Fibrin formation is also documented by images showing intricate networks indicative of blood coagulation. In conclusion, the genesis of hair shafts bipolarity is shown resulting from a "gap" in the follicle electromagnetic fields inhibiting energy from fully engulfing the shaft.

Keywords: Potassium Blocking Rejection, Hair Follicle, Bipolar Hair Shaft, Hair as dc Battery, Hemocoagulation, Shepherds Hook Genesis, Tissue DC Currents, Hair Follicle Gap, Hair External Electromagnetism

\section{Definition of Terms}

DC = Direct Current.

$\mathbf{K}_{3} \mathbf{F e}=$ Acronym for Potassium Ferricyanide $\mathrm{K}_{3}\left[\mathrm{Fe}(\mathrm{CN})_{6}\right]$.

$\mathbf{E M R}=$ Electromagnetic Radiation

\section{INTRODUCTION}

The human hair consists of a follicle anchored in the skin and a protruding shaft, it has also been described as a miniorgan, having its own cell divisions, metabolism, and known to undergo aging stages (Schneider et al. (2009)); eventually reaching a point where the old hair sheds and a new hair growing cycle begins from the same follicular tissue. Using sophisticated magnetometers, magnetic field emitted by direct current (DC) in human hair follicles were detected and introduced in 1980 (Cohen et al. (1980)). Most recently in 2015, a tabletop optical microscopy method was developed and published in 2016, thus allowing for the detection of hair follicles and shaft magnetic fields (Scherlag et al. (2016)). When a hair shaft is in contact with fresh blood tissue on a slide, an interesting finding occurs, which is one side inducing blood coagulation and the opposite side inhibiting of coagulation. 


\section{MATERIALS AND METHODS \\ 2.1. MATERIALS}

Potassium Ferricyanide $\mathrm{K}_{3}\left[\mathrm{Fe}(\mathrm{CN})_{6}\right]$.

25x75x1 mm glass slides

Fresh human blood smear

Freshly in toto plucked scalp human hair

Demineralized bottle water

Celestron Video Microscope Model \# 44348

MacBook Pro Apple computer with Photo Application software.

\subsection{METHODS}

1) A fresh human blood smear obtained. Solution prepared by diluting approximately 2 milligrams of $\left(\mathrm{K}_{3} \mathrm{Fe}\right)$ diluted in one drop of demineralized water was added to the center of a wet smear*.

Note: ${ }^{*}$ A finger stick allowed for the milking of two drops of blood, then placed on a clean $25 \times 75 \times 1 \mathrm{~mm}$ glass slide. The mechanical smear was done as per published instructions from the USA center for disease control. There is a time window of approximately $60 \pm 20$ seconds for a complete preservation of in vivo properties of the blood tissue. For details link to: (https://doi.org/10.5281/zenodo.3472760)

2) One freshly tweezers plucked scalp hair was carefully placed in approximately the area where the of the liquid $\mathrm{K}_{3} \mathrm{Fe}$ had displaced the blood tissue.

3) The preparation allowed evaporating, Images recorded and stored for analysis.

\section{RESULTS AND DISCUSSIONS}

Prior research by this author showed the follicle and shaft magnetic fields properties on a glass slide (in the absence of blood) with the addition of only liquid $\mathrm{K}_{3} \mathrm{Fe}$, as shown in images showing the hair shaft unilateral presence of electromagnetic radiation (EMR) (Embi (2018)) (Figure 2). In this manuscript, qualitative images are presented where not only the bipolar electrical property of the shaft is documented; but also showing EMR originating from the hair follicle routed only to one side of the shaft, a gap in the hair follicle's EMR continuity accounting for the shaft's bipolarity (+-) (Figure 2, Figure 3).

\section{Potassium as Immunosuppressing Agent}

The rejection of several exogenous materials, such as a hair follicle, keratin flakes and small iron filings amongst others by a fresh human blood smear had been described, Figure 7 ( Embi (2018)).

In this manuscript, the addition of liquid $\mathrm{K}_{3} \mathrm{Fe}$ to a fresh human blood smear inhibited rejection of an in toto hair (follicle and shaft). This inhibition allowed for images such as in (Figure 2, Figure 3, Figure 4, Figure 5). The question arises: What is the mechanism whereby addition of liquid $\mathrm{K}_{3} \mathrm{Fe}$ to a fresh blood smear inhibits fresh blood from rejecting a hair follicle? 
Perhaps some elucidation could be explained by findings where a link between tumor-induced immune suppression by the Potassium ion $\left(\mathrm{K}^{+}\right)$exists (Vodnala et al. (2019)).

\section{$\mathrm{K}_{3} \mathrm{Fe}$ Total Absorption of Incoming EMRs \\ Hair Shaft Polarity and Blood Coagulation}

Liquid $\mathrm{K}_{3} \mathrm{Fe}$ allowed for the display of hair follicle and shaft EMR as shown (Figure 2, Figure 4). A second important observation is the findings or previous papers correlating a positive charge with blood coagulation. Early in 2018, an image was recorded showing what appeared to be a one-sided electrical discharge in a human hair shaft. (Figure 1). In 2018 there was not enough published experimental data found by this author to support a hair shaft bipolarity finding.

The question arose: How could a keratin surrounded filamentous structure express opposite sides charges?

\section{Prior Publication Hinting at Bipolarity \\ Potassium Ferrocyanide Spatially Detachment of Shaft Exo-Cuticles}

A paper published in 2016, showed that when a human hair shaft was sandwiched between two glass slides and covered by Potassium Ferrocyanide (Embi (2016)), post evaporation, microscopy images showed an unexplained phenomenon, being the spatially separated images of hair exocuticles. In other words, there was a need of a microscope depth of field adjustment to bring the cuticles layers in focus as shown in Figure 6 below.

Evidence shows that the addition of one drop of liquid $\mathrm{K}_{3} \mathrm{Fe}$ onto a fresh blood smear inhibited rejection of a foreing material, namely a plucked human hair. This inhibition, allowed for the identification of the hair EMRs. This is supported by a property of $\mathrm{K}_{3} \mathrm{Fe}$ being the "Full absorption od incoming EMRs" ( Figgis et al. (1969), Baranov et al. (2015))

The hair unique electromagnetic radiation pattern is shown partially engulfing the follicle. There is a "gap" shown in the images that does not allow the magnetic signal from traveling to one side of the hair shaft. The Hair Shaft Inherent Unilateral Divergent Charges (+-) are displayed.

\section{The Dual Consequences of Follicle's EMR Gap}

First) The abrupt interruption of EMRs in one side of the hair follicle, accounts for the hair shaft's one-sided EMR activity triggering positive charges.

Second) The genesis of a visual display resembling a "Shepherd Hook" pattern of the human hair EMR emissions. 


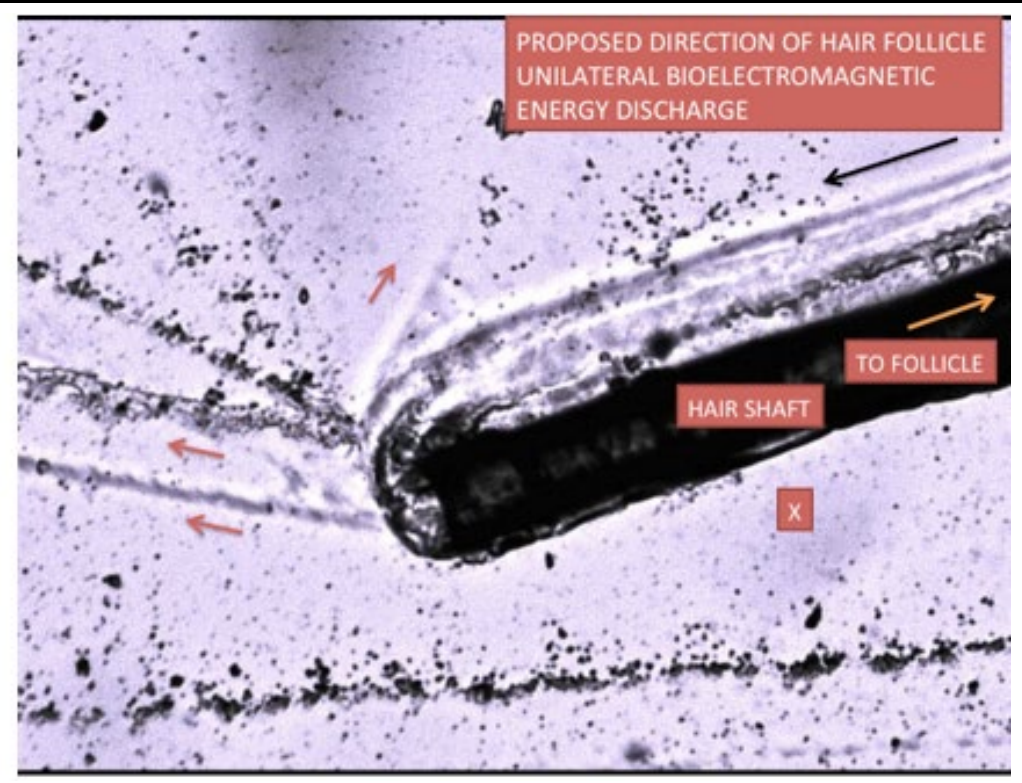

Figure 1 Hair shaft sanwiched between glass slides and covered by drops potassium Ferrocyanide in solution. Showing shaft unilateral discharge of elecromagnetic energy. Black Arrow: Direction of forces- X: Shaft side void of energy.

Hair on Slide Covered by Potassium Ferricyanide. Hair Physically Removed by Tweezers Showing Absence of . Crystals in Hair Shaft Negative Side. I

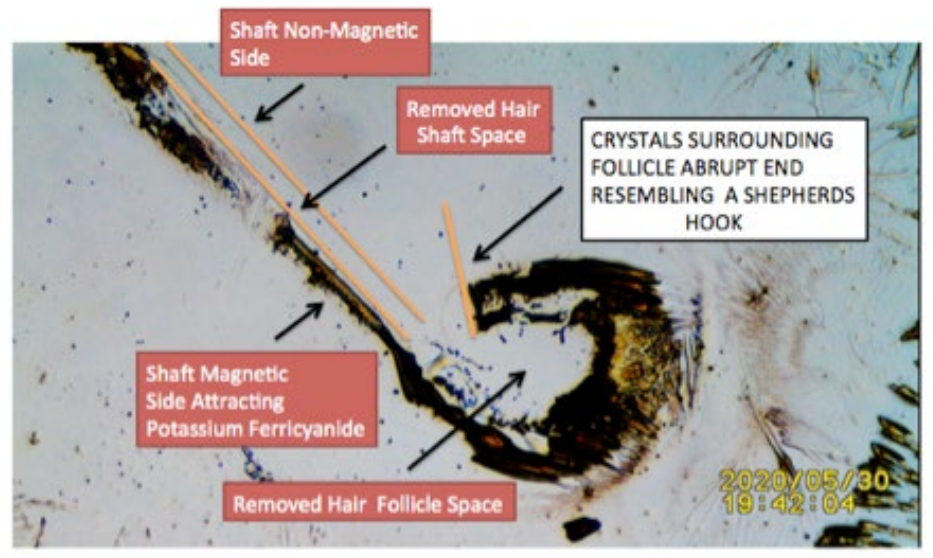

Figure 2 Image of hair imprint surrounded by human blood tissue mixed with potassium Ferricyanide crystals. Notice the EMR unable to fully reach one side of the hair shaft (orange line).

Image reproduced from: Embi, AA (2021). Some curious findings hair follicles bioelectromagnetic radiation expressed as light displacing matter in its path and the contralateral emission of magnetic fields found in the hair shaft. International 
Another Hair Placed on Human Blood Smear Plus Liquid Potassium Ferricyanide Drops

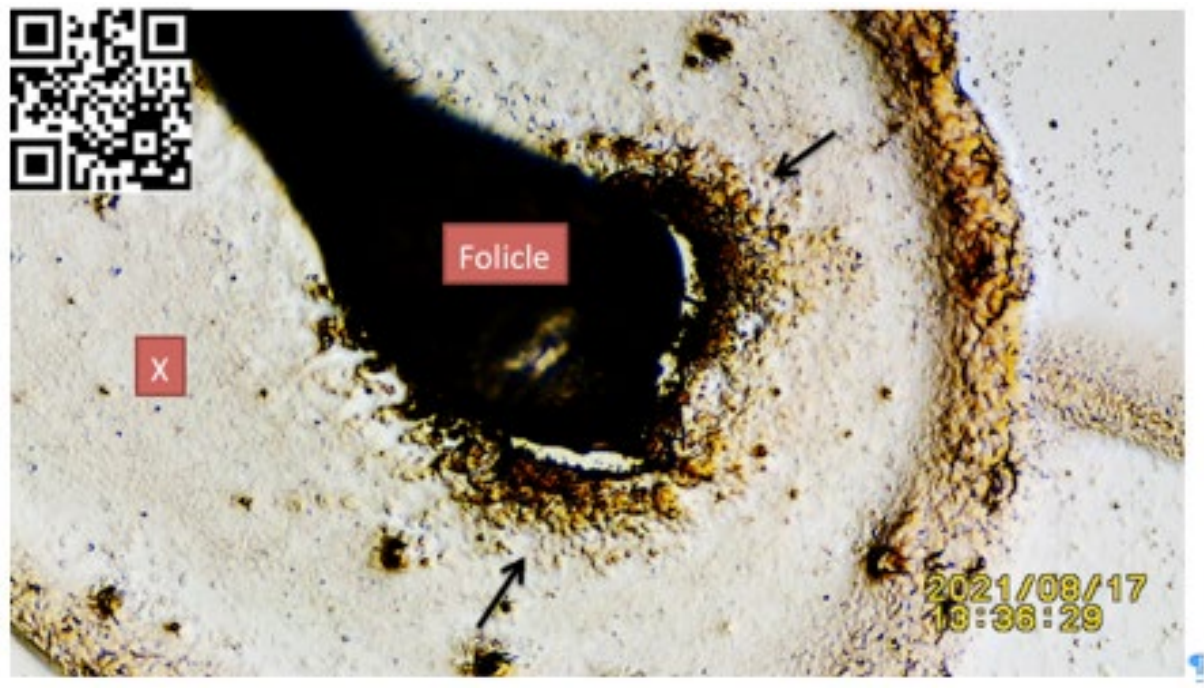

Figure $3 \mathrm{~N}=2$ Hair on fresh human blood smear, post addition of $\mathrm{K}_{3} \mathrm{Fe}$ allowing for this demonstration. Black Arrow: Pointing at mix of $\mathrm{K}_{3} \mathrm{Fe}$ crystals and coagulated blood surrounding follicle prior removal via tweezers.

For further details link to: https://youtu.be/LLz43yAbpg0....or Scan QR Code in left upper corner of image

Same Hair as in Figure 3 Above. Hair Removed via Tweezers Showing Follicle's Imprint Delineating EMRs Abruptly Ending Prior to Surrounding the Follicle. Red line indicating, "gap" void of EMRs.

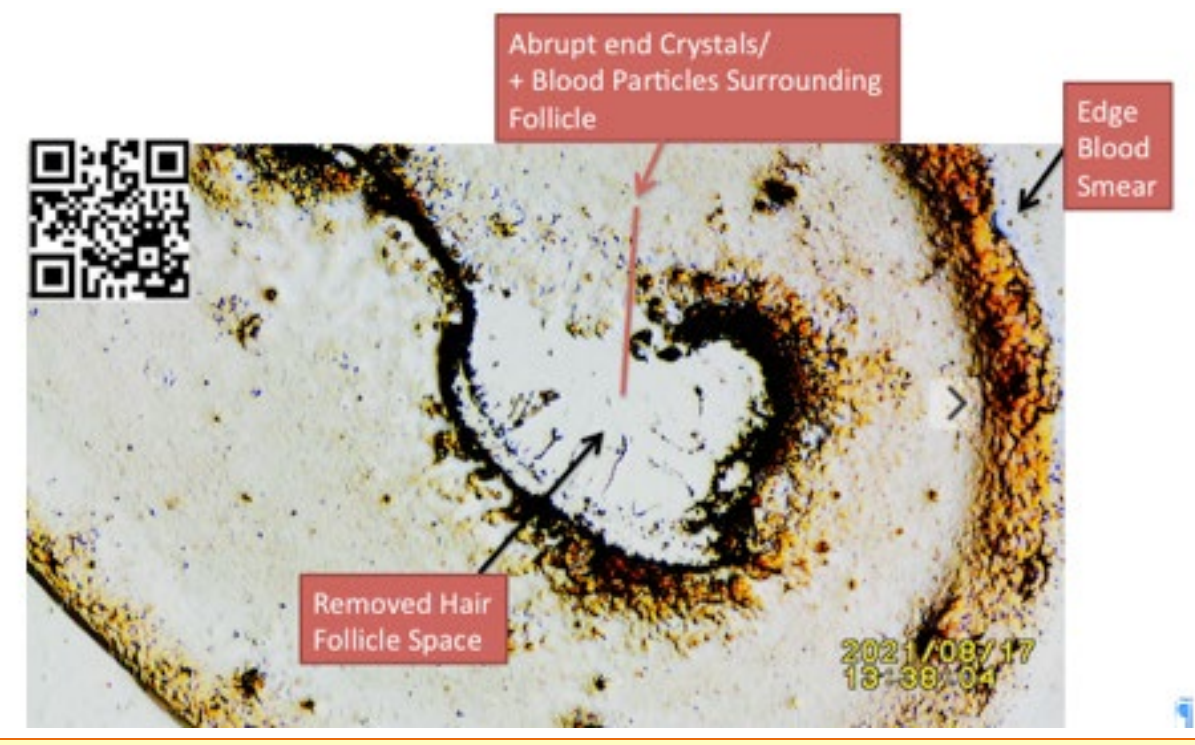

Figure 4 image introduced in this manuscript showing Hair EMR outline after hair removed. Black Arrows: Pointing at mix of crystals and coagulated blood plus edge of blood smear. The abrupt end of EMRs circumventing the follicle is shown. 
For details link to: https://youtu.be/LLz43yAbpg0....or Scan QR Code in left upper corner of image.

Amplified Image of Figure 4 above

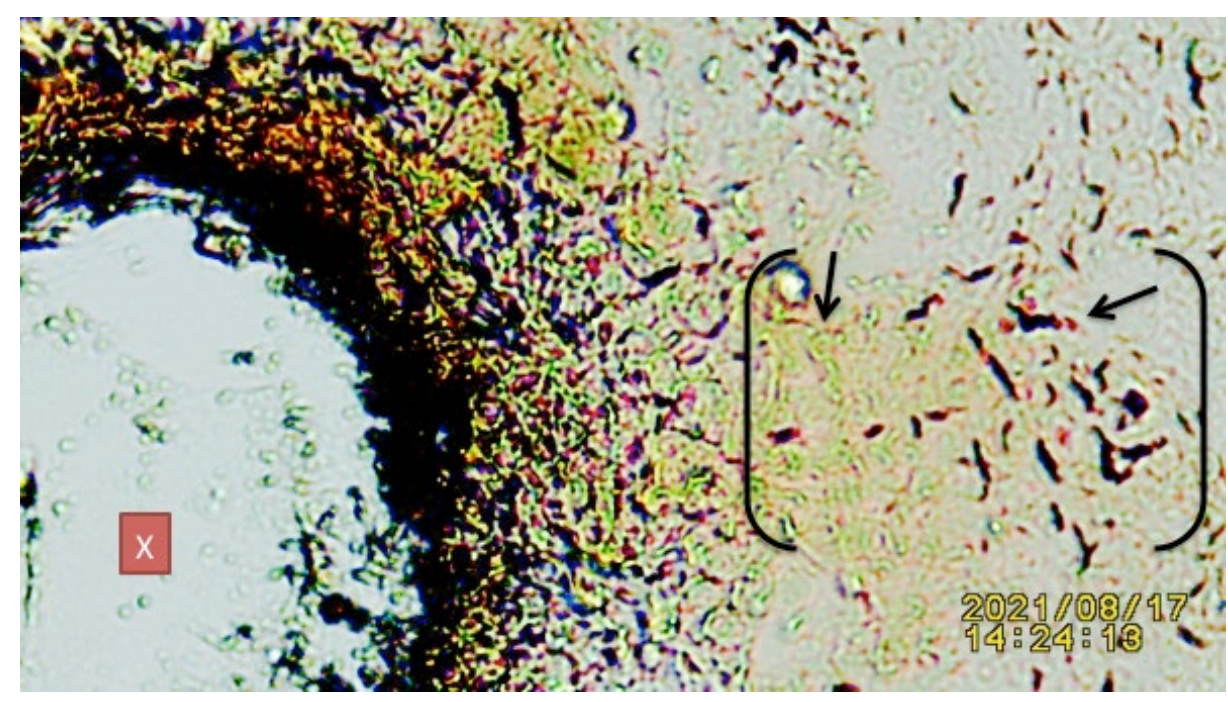

Figure 5 Amplified image of Fig 4, showing X= Some blood tissue trapped under hair follicle. Brackets $=$ Showing mix of blood tissue (RBCs) and fibrin.

Image published in 2016 Hinting at Bipolarity of Hair Shaft Exocuticles

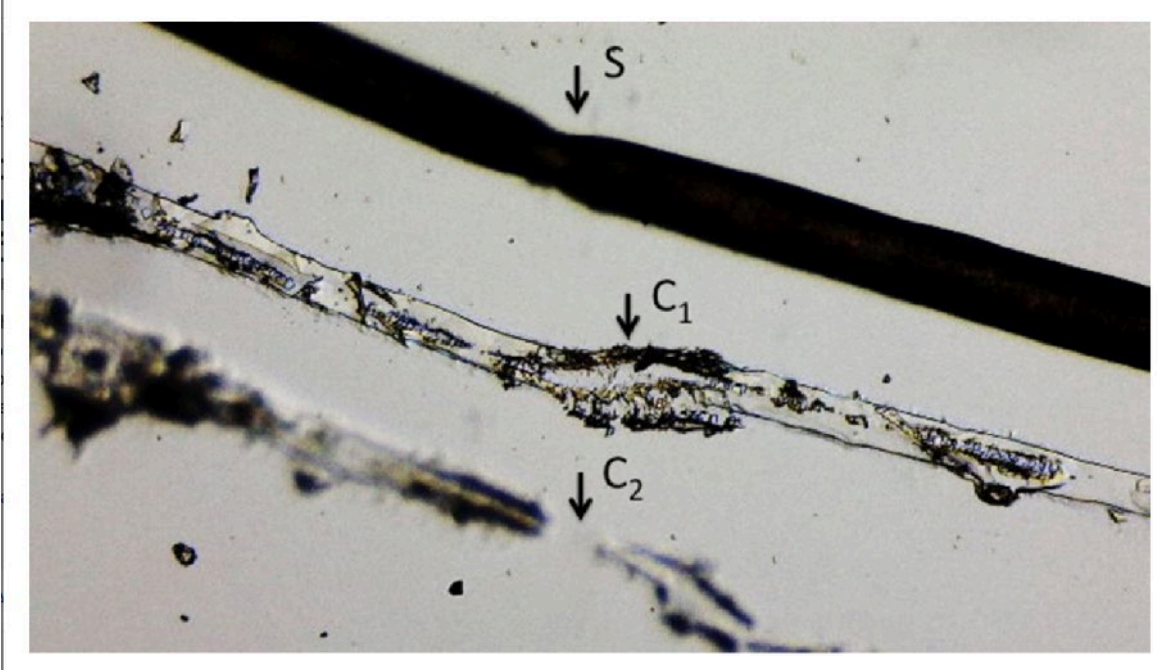

Figure 6 Microphotograph of hair in contact with Prussian Blue (PBS) between two glass slides (SDW) after evaporation, showing: S= Shifting shaft showing damage caused by tweezers, $\mathrm{C} 1=\mathrm{In}$ focus damaged anterior level cuticles, $\mathrm{C} 2$ = Out of focus damaged posterior level cuticles (out of focus). X4 Magnification.

Image reproduced from:

Embi AA. Adhesion Failure of External Hair Cuticles Caused by Prussian Blue: Possible Electrochemical Roles of Sulfur and Cystine. J Nat Sci, 2(6):e194, 2016. 
Image of Fresh Human Blood Smear Repulsing Hair Follicle

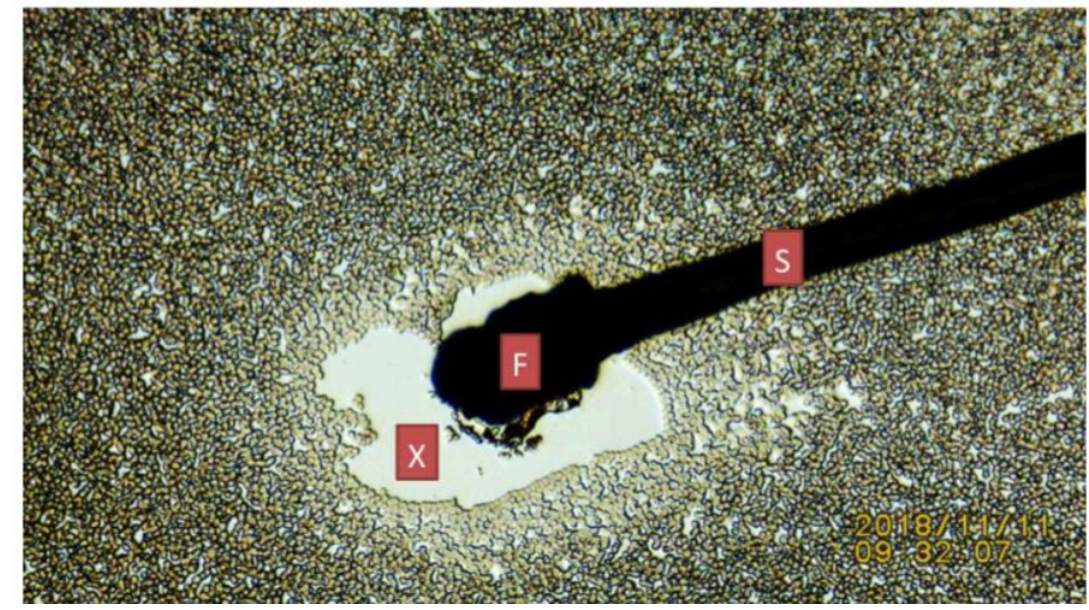

Figure 7 Image depicting fresh human blood smear rejecting hair follicle. $\mathrm{F}=$ Follicle. $\mathrm{X}=$ Empty space due to repulsive phenomenon.

Image reproduced from: Cite This Article: Abraham A. Embi Bs. (2018). "BIOMAGNETISM AS FACTOR IN RED BLOOD CELLS DEFORMATION." International Journal of Research - Granthaalayah, 6(12), 46-57. https://doi.org/10.29121/granthaalayah.v6.i12.2018.1245.

Image published in 2018 of Hair Shaft on Fresh Blood Smear Showing Effect of Positive Pole on Coagulation

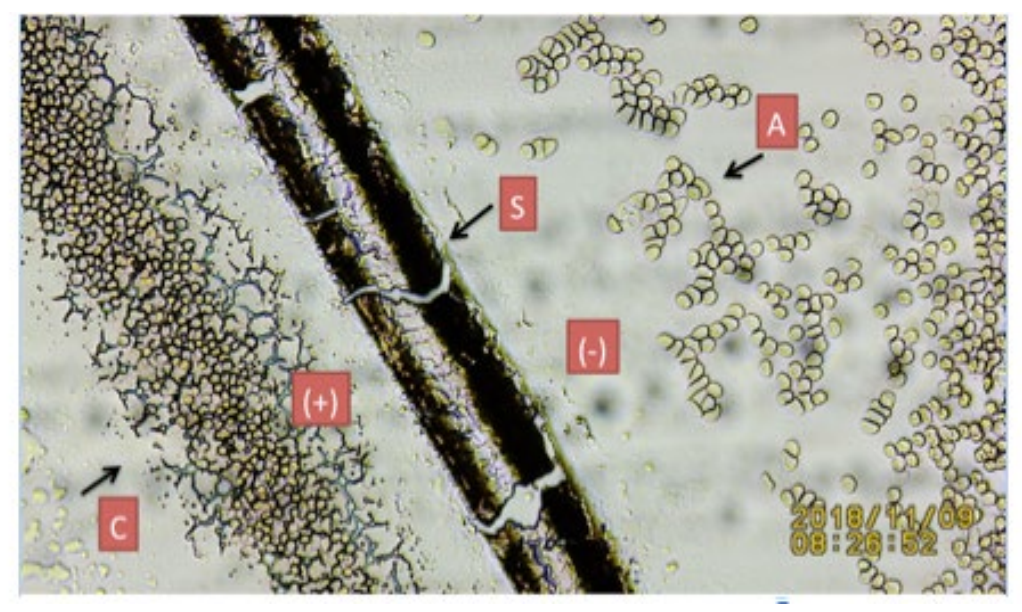

Figure 8 Microphotopraph depicts detached hair shaft outline.

A= Non-coagulated blood $\mathrm{S}=$ Hair shaft $\mathrm{C}=$ Coagulated blood.

$(-)=$ Negative pole $\mathrm{RBC}$ repulsion. $(+)=$ Positive pole attracting $\mathrm{RBCs}$ (coagulation). Reproduced from:

Abraham A. Embi Bs. (2018). "HAIR AND BLOOD ENDOGENOUS LOW LEVEL BIOMAGNETIC FIELDS CROSS-TALK EFFECTS ON FIBRIN INHIBITION AND 
ROULEAU FORMATION." International Journal of Research - Granthaalayah, 6(11), 200-208. https://doi.org/10.29121/granthaalayah.v6.i11.2018.1118.

\section{SUPPLEMENTAL INFORMATION}

Upon re-visiting my files, found some video-recordings where the hair was physically removed from the glass smear- Since the hair had been covered by Potassium Ferricyanide $\left(\mathrm{K}_{3} \mathrm{Fe}\right)$ in solution; and $\mathrm{K}_{3} \mathrm{Fe}$ has the property of full absorption of incoming electromagnetic radiation (EMR), the hair outer layers EMR are shown as $\mathrm{K}_{3} \mathrm{Fe}$ crystals. These images are introduced for the first time in this manuscript- Notice the consistent narrowing between the distal follicle and the bulb-

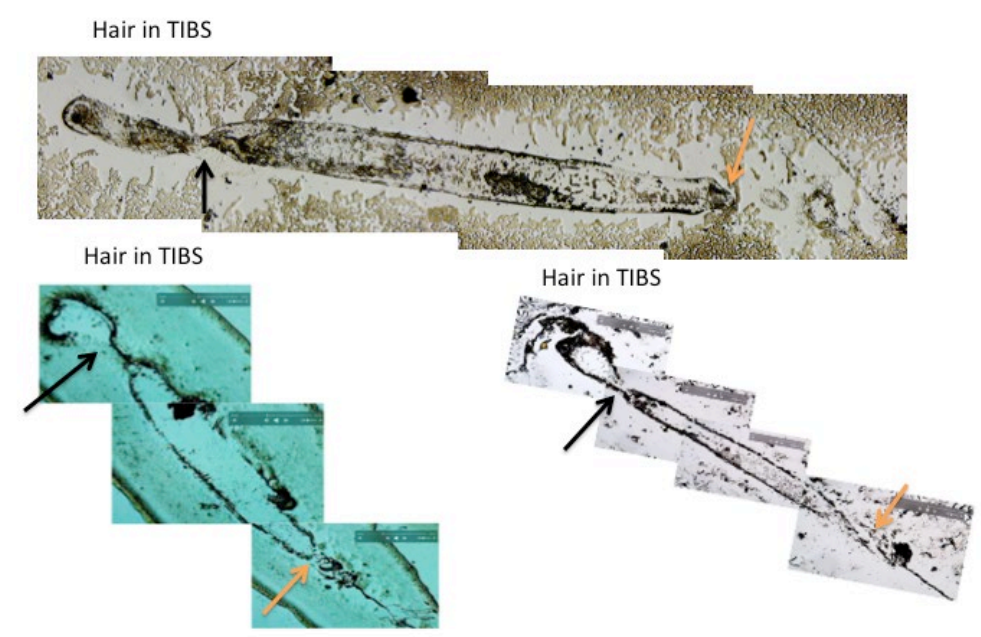

Figure 9 Showing sequential images from video-recordings outlining the human hair external electromagnetic radiation. Black Arrows: Notice the narrowing shown between the distal follicle and the bulb also showing a gap in energy continuity. This gap is theorized to induce the bipolar nature of the shaft (+-). TIBS= Temporary In Vivo Blood Smear. Orange Arrows: Pointing at area where shaft exits towards skin.

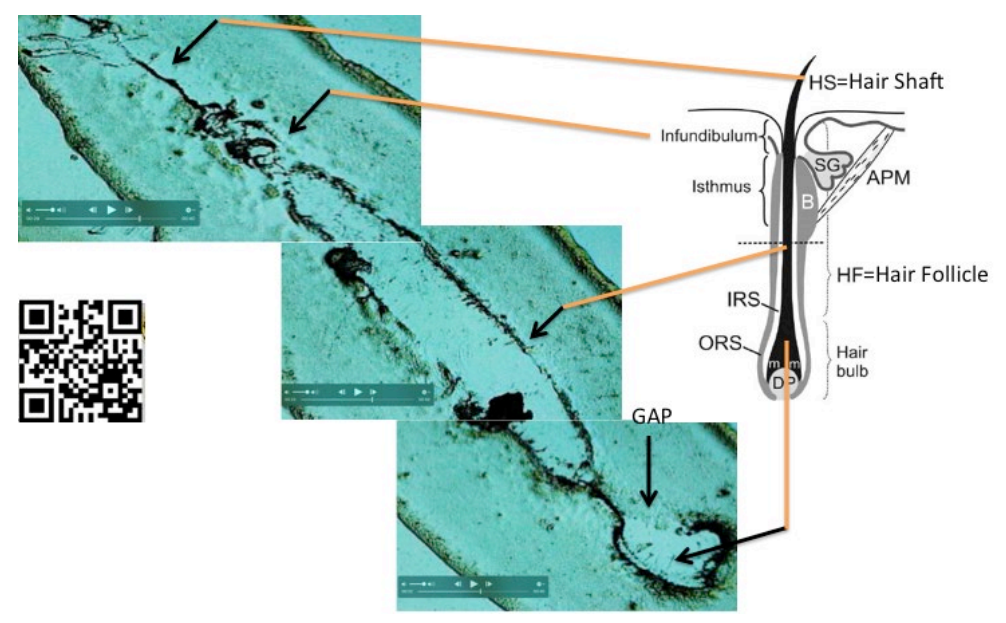

Figure 10 Cut and Paste frames to illustrate the human scalp hair magnetic imprint post hair removal from slide. Scalp hair in fresh blood smear mixed with liquid Potassium Ferricyanide. After drying, outer layers of hair are delineated showing hair anatomical areas. Human hair magnetic Imprint on glass slide. Drawing on right side of figure reproduced as described in the copyright fair use doctrine. 
Credit of drawing given to: Pisal Rishikaysh et al. DOI: doi:10.3390/ijms15011647

For video detais link to:: https://youtu.be/LLz43yAbpg0 Or scan QR Code in left side of Figure 4.

\section{REFERENCES}

Abraham A. Embi Bs. (2018). "BIOMAGNETISM AS FACTOR IN RED BLOOD CELLS DEFORMATION.” International Journal of Research - Granthaalayah, 6(12), 46-57. Retrieved from https://doi.org/10.29121/granthaalayah.v6.i12.2018.1245.

Abraham A. Embi Bs. (2018). "THE HUMAN HAIR FOLLICLE PULSATING BIOMAGNETIC FIELD REACH AS MEASURED BY CRYSTALS ACCRETION." International Journal of Research - Granthaalayah, 6(7), 290-299. Retrieved from https://doi.org/10.5281/zenodo.1341349.

Abraham A. Embi Bs. (2018). “THE SHEPHERDS HOOK PHENOMENON PATTERN OF HAIR ROOTS A DEMONSTRATION OF COMPARATIVE BIOLECTROMAGNETISM BETWEEN HUMAN HAIRS AND MOUSE WHISKERS BY MEANS OF THE PHOTOELECTRIC EFFECT." International Journal of Research - Granthaalayah, 6(7), 317-326. Retrieved from https://doi.org/10.29121/granthaalayah.v6.17.2018.1312.

B. N. Figgis, Malcolm Gerloch, Ronald Mason, and Ronald Sydney (1969) Nyholm the crystallography and paramagnetic anisotropy of potassium ferricyanide. https://doi.org/10.1098/rspa.1969.0031 Retrieved from DOI: https://doi.org/10.1098/rspa.1969.0031

Cohen, D., Palti, Y., Bn, C. \& Sj, S. (1980). Magnetic Fields Produced By Steady Currents In The Body. Proc. Natl. Acad. Sci 77(3), 1447-1451. Retrieved from https://doi.org/10.1073/pnas.77.3.1447

Embi AA (2016). Adhesion Failure of External Hair Cuticles Caused by Prussian Blue: Possible Electrochemical Roles of Sulfur and Cystine. J Nat Sci, 2(6):e194.

D. G. Baranov, J. H. Edgar, Tim Hoffman, Nabil Bassim, Joshua D. Caldwell (2015). Perfect interferenceless absorption at infrared frequencies by a van der Waals crystal. DOI: 10.1103/PhysRevB.92.201405 Retrieved from DOI: https://doi.org/10.1103/PhysRevB.92.201405

Scherlag, B.J., Sahoo, K., Embi, A.A (2016). A Novel and Simplified Method for Imaging the Electromagnetic Energy in Plant and Animal Tissue. Journal of Nanoscience and Nanoengineering 2(1): 6-9.

Schneider MR, Schmidt-Ullrich R, Paus R (2009). The hair follicle as a dynamic miniorgan. Curr Biol. Feb 10;19(3): R132-42. Retrieved from doi: 10.1016/j.cub.2008.12.005. Retrieved from https://doi.org/10.1016/j.cub.2008.12.005

Vodnala S.K., Eil R., Kishton R.J., Sukumar M., Yamamoto T.N., Ha N.H., Lee P.H., Shin M., Patel S.J., Yu Z., Palmer D.C., Kruhlak M.J., Liu X., Locasale J.W., Huang J., Roychoudhuri R., Finkel T., Klebanoff C.A., Restifo N.P (2019). T cell stemness and dysfunction in tumors are triggered by a common mechanism.Science. Mar 29. Retrieved from https://doi.org/10.1126/science.aau0135 